\title{
The Effect of Grape Temperature on the Sensory Perception of Méthode Cap Classique Wines
}

\author{
M. Mafata ${ }^{1,2}$, A. Buica ${ }^{1,3}$, W. du Toit ${ }^{1}$, V. Panzeri ${ }^{3}$, F.P. van Jaarsveld ${ }^{2 *}$ \\ (1) Department of Viticulture and Oenology, Stellenbosch University, Private Bag X1, Matieland 7602, South Africa \\ (2) Post-Harvest \& Wine Technology, ARC Infruitec-Nietvoorbij, Private Bag X5026, Stellenbosch 7599, South Africa \\ (3) Institute for Grape and Wine Sciences, Stellenbosch University, Private Bag X1, Matieland 7602, South Africa
}

Submitted for publication: September 2017

Accepted for publication: November 2017

Keywords: Méthode Cap Classique, traditional sparkling wine, free sorting, Chardonnay, Pinot Noir, temperature

\begin{abstract}
The production process of South African bottle-fermented sparkling wine, the Méthode Cap Classique (MCC), follows the traditional French method (méthode champenoise), although each cellar has its own unique additions to the method. South African winemakers use different techniques and blends to achieve their award-winning MCCs, but there have not been many scientific investigations of the science behind these wines. This project is one of the first scientific studies on MCC. MCC wines were made using Chardonnay and Pinot Noir grapes harvested over two vintages (2014 and 2015) from two regions (Robertson and Darling) and stored at $0^{\circ} \mathrm{C}, 10^{\circ} \mathrm{C}, 25^{\circ} \mathrm{C}$ and $30^{\circ} \mathrm{C}$ before processing. The study was aimed at investigating the effect of grape storage temperature on the sensory characteristics of MCCs. The aroma and taste of the final nine-month old MCCs were evaluated, with each region analysed separately. The study showed a grouping of the MCCs according to temperature treatments for both vintages. There were vintage differences in terms of the attributes cited and the frequency of citations. Based on the frequency of citation, the MCCs made 2014 from grapes stored at $0^{\circ} \mathrm{C}$ and $10^{\circ} \mathrm{C}$ were described by the judges as having a fruity, fresh and crisp aroma, whilst those made from grapes stored at $25^{\circ} \mathrm{C}$ and $30^{\circ} \mathrm{C}$ were described as having oxidised fruit, volatile acidity and solvent-like aromas. The judges perceived less oxidation and volatile acidity (VA) (in terms of the frequency of citation) in the aroma of the 2015 MCCs, although treatments at higher temperatures were still associated with less desirable attributes compared to treatments at lower temperature. This study shown that the temperature of the grape at the time of processing has a significant effect on the aroma of MCCs aged nine months, and not so much of an effect on the taste.
\end{abstract}

\section{INTRODUCTION}

The first sparkling wine in South Africa was released in 1971 (Newton, 2010). The South African Cap Classique Producers Association (CCPA), formed for the appreciation of Méthode Cap Classique (MCC) traditional-style sparkling wines (TSW), was established in 1992 and has since contributed to the growth of these wines, which are on an equal footing with those in the international market. Sparkling wine made in the traditional method is predominantly produced from the cultivars Chardonnay, Pinot Noir and Pinot Meunier in France, California, Australia and South Africa (Zoecklein, 2002). The Spanish, Italians and Germans use native grape varieties to produce their sparkling wines (MartínezLapuente et al., 2013). The traditional method of sparkling winemaking is referred to as méthode traditionnelle and méthode classique in French regions aside of Champagne, méthode champenoise in the Champagne region of France, metodo classico in Italy, and méthode Cap Classique in
South Africa (Zoecklein, 2002). The distinguishing feature of sparkling wines is the second alcoholic fermentation, which creates the desired bubbles in the wine. The second fermentation distinguishes traditional methods of sparkling winemaking (fermentation in the bottle) from the Charmat method (fermentation in tanks) and carbonated sparkling wine, in which $\mathrm{CO}_{2}$ is bubbled into the base wines (Zoecklein, 2002; Anderson et al., 2008; Martinez-Lapuente et al., 2013).

A schematic of the TSW winemaking process is presented in Fig. 1. The grapes are harvested early, at a low berry sugar content ( $17^{\circ}$ to $20^{\circ}$ Balling) compared to table wines because of the double alcoholic fermentation (Anderson et al., 2008; Martinez-Lapuente et al., 2013). Grapes are usually pressed as whole bunches at a low pressure $(\leq 1.5$ bars $)$ to retrieve the juice, which is then fermented at between $12^{\circ} \mathrm{C}$ and $15^{\circ} \mathrm{C}$, resulting in the base wines (Zoecklein, 2002). The liqueur de tirage is added to sweetened the base wine (20 to

*Corresponding author: E-mail address: VJaarsveldF@arc.agric.za

Acknowledgments: The authors wish to thank the Groote Post, Graham Beck and Charles Fox farms, as well as winemakers Mr Pieter Ferreira, Mr Hannes Meyer and Mr Craig Paulsen, without whom this project would not have been possible. 


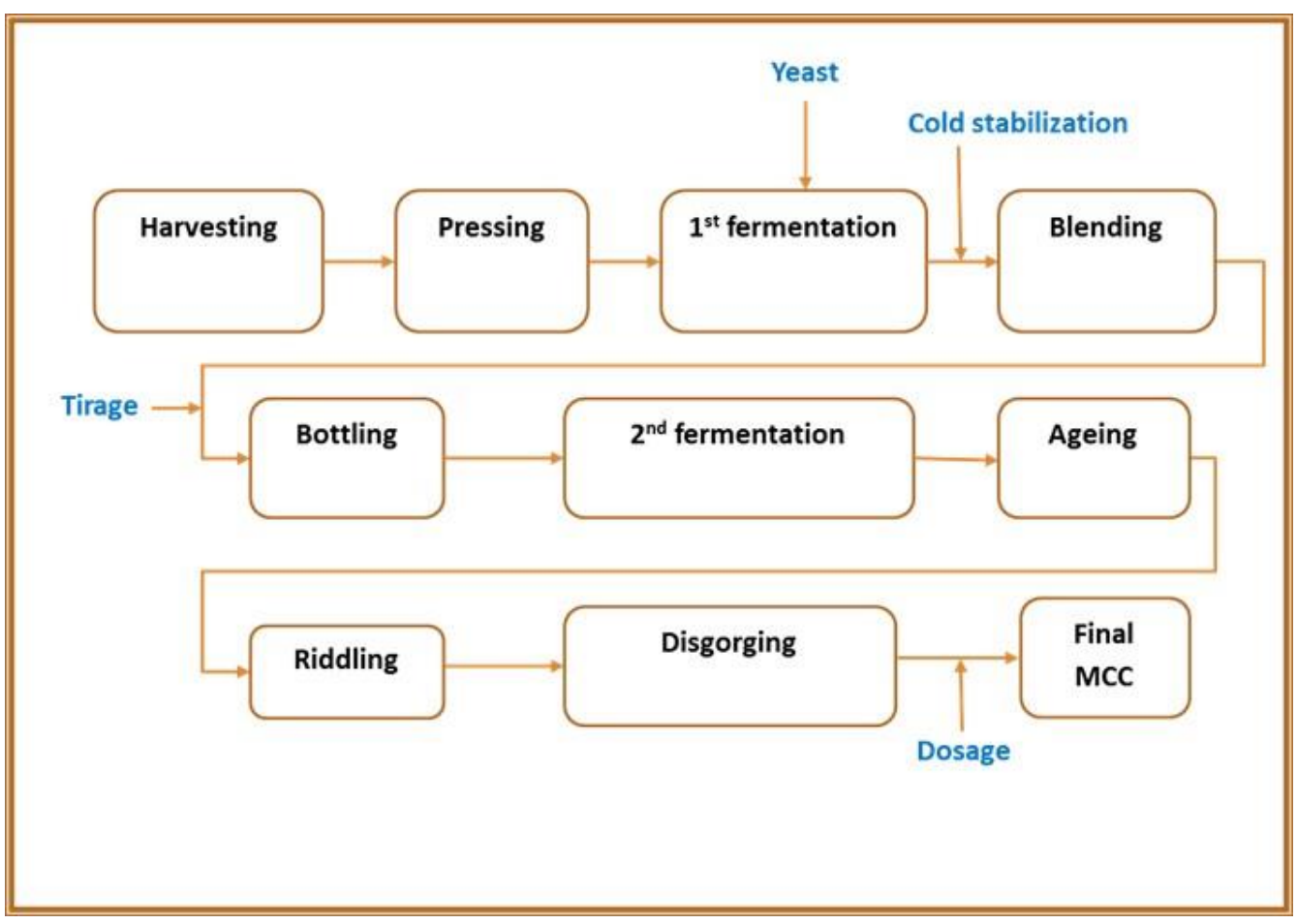

FIGURE 1

A flow diagram of the stages in the traditional sparkling winemaking process.

$24 \mathrm{~g} / \mathrm{L}$ sugar), which are immediately bottled for the second fermentation. The liqueur de tirage is a mixture of rehydrated yeast, sugar and base wine incubated at $14^{\circ} \mathrm{C}$, with periodic sugar addition and aeration. The second fermentation in the bottle proceeds for four to eight weeks at between $14^{\circ} \mathrm{C}$ and $18^{\circ} \mathrm{C}$. The wines are bottle-aged for nine months or longer, and are thereafter riddled and disgorged off the lees. Riddling requires the rotation of individual bottles around their central axis at an incline of $45^{\circ}$, either manually or using gyro pallets, thereby allowing the lees to collect at the mouth of the bottle. Disgorging entails the removal of the collected lees, followed by immediate corking or recapping of the bottle. Traditionalstyle sparkling wines have to be riddled and disgorged off the lees in the same bottle as they are sold in. Traditionalstyle sparkling wine is aged for nine months or longer on the lees (OIV, 2016). The Charmat method and carbonated sparkling wines do not require riddling or disgorging. The ageing of Charmat-style sparkling wine continues for a few days to some weeks, while carbonated sparkling wines require no ageing process. The production processes of these two methods are optimised to meet consumer demands by allowing for the production of larger volumes and cutting out the riddling and disgorging processes. The dosage (liqueur de dosage) is added to the dry wine in order to give the wine more flavour and sweeten it to the winemaker's preference. Brut sparkling wines (dry wines) require no dosage post disgorging (Zoecklein, 2002).

Sparkling wines have a very interesting and unique matrix that is not directly comparable to that of still wines due to the dissolved $\mathrm{CO}_{2}$, which creates the iconic effervescence. The sensory evaluation of sparkling wine therefore is very different from that of table wines, precisely because of the effervescent nature of the wines. In previous studies, the bottle pressure has been shown to have little impact on the foam quality and aroma intensity, but a link between the chemical composition (not including phenolics) and foam properties has been found (Pueyo et al., 1995).

Attributes such as olfactory intensity, fruitiness (exotic and citrus fruits), varietal aromas, and floral, vegetal, yeasty, mouldy, reductive and oxidized notes are cited more in young TSW (Pérez-Magarino et al., 2013), whilst attributes such as toasty, buttery, caramel and butterscotch are more sought after in sparkling wines aged older than nine months (Francioli et al., 2003). During ageing on the lees and extended lees contact, the degeneration of yeast cells after fermentation results in the release of yeast cell products like polysaccharides, glycoproteins, lipids and nucleic acids (Feuillat \& Charpentier, 1982; Martínez-Rodriguez et al., 2001; Fornairon-Bonnefond et al., 2002). These yeast autolysis products have a distinct sensorial character, referred to as the "autolytic character", which has previously been associated with attributes such as toasty, bread, butter and butterscotch. The proteins released during yeast autolysis have previously been connected to the perception of a 'fuller body' in wines (Martínez-Rodriguez et al., 2002; MartínezRodriguez \& Pueyo, 2009). Charpentier et al. (2005) showed a link between yeast cell-derived nucleic acids, the release of yeast cellular contents (during autolysis and hydrolysed intracellularly by enzymatic reactions) and SW mouthfeel and flavour.

There is no published or recommended method for the sensory evaluation of TSW, but guidelines have fairly recently been provided on how to ensure uniformity in the evaluation of TSW across judges when taking the effervescence into account (Buxaderas \& López-Tamames, 2010; White et al., 2015). The time between pouring and 
tasting has to be minimised, as it has been shown to have an impact on the sensory perception of sparkling wine. Panel uniformity (in terms of an equal amount of wine poured), randomisation and time between tasting and pouring need to be ensured as far as possible (White \& Heymann, 2015). Sensory evaluation studies performed on TSW have mostly used descriptive analysis (DA), a very useful tool that allows for the generation of sensory descriptors along with their perceived intensities. However, DA can be costly, time consuming and labour intensive. It requires tasters to be trained, and only a few wines can be tasted at a time, as panel fatigue can occur when many wines are presented in one session (Vannier et al., 1999; Hidalgo et al., 2004; Polidori et al., 2009). Sorting analysis can be performed without a trained panel and can allow for more wines to be evaluated (Chollet et al., 2014). Free sorting has previously been used on beer, which has effervescence similar to MCCs (Chollet, et al., 2011), but it has not previously been used in the evaluation of TSW. Studies have found that harvest (Marais, 2001) and fermentation (Reynolds et al., 2001) temperatures affect the colour and aroma of table wines, but due to matrix differences a direct assumption cannot be made about TSWs based on still wine behaviour. This study investigated the effect of grape temperature at pressing on the aroma and taste of MCC wines made through wholebunch pressing and aged on the lees for nine months. The sorting method was used as a way to evaluate the different treatments sensorially.

\section{MATERIALS AND METHODS \\ Vinification}

Chardonnay and Pinot Noir grapes were harvested in the early morning from Robertson and Darling in 2014 and 2015 and transported on the day to the ARC Infruitec-Nietvoorbij experimental cellar (Stellenbosch, South Africa). For each region and for each cultivar, two tons of grapes were divided into four batches and stored in temperature-controlled rooms at $0^{\circ} \mathrm{C}, 10^{\circ} \mathrm{C}, 25^{\circ} \mathrm{C}$ and $30^{\circ} \mathrm{C}$ until they acclimatised to the set temperature. Digital temperature probes were inserted into and between the grapes to ascertain that the grapes had reached and maintained the set temperature.

Each batch was further divided into three repeats, the grapes were whole-bunch pressed at 1.0 to 1.5 bar into $90 \mathrm{~L}$ drums, and $50 \mathrm{mg} / \mathrm{L} \mathrm{SO}_{2}$ was added. The juice was stored overnight at $14^{\circ} \mathrm{C}$ to acclimatise to the fermentation temperature, was inoculated with $0.3 \mathrm{~g} / \mathrm{L} S$. cerevisiae IOC18-2007 (CDS Vintec, Stellenbosch, South Africa) yeast, and $0.5 \mathrm{~g} / \mathrm{L}$ diammonium phosphate (DAP) was added. The wines were left to ferment at $14^{\circ} \mathrm{C}$ and the fermentation was tracked by measuring the pressure in the bottle. Once the fermentation was finished, the wines were racked and 50 $\mathrm{mg} / \mathrm{L}$ of $\mathrm{SO}_{2}$ was added. The base wines were clarified using $0.75 \mathrm{~g} / \mathrm{L}$ bentonite, after which they were cold stabilised at $0^{\circ} \mathrm{C}$ for two weeks and racked once more. The corresponding Pinot Noir and Chardonnay treatments were then blended in a 50/50 ratio and allowed to stand for a further week before being sweetened to $24 \mathrm{~g} / \mathrm{L}$ with cane sugar, inoculated with a $4 \%$ liqueur de tirage made up of the same yeast as for the first fermentation, bottled under nitrogen gas and capped with a crown capper. The second fermentation was tracked by measuring the pressure in the bottle, with one bottle per treatment being sacrificed at each test. Once the pressure stabilised, the fermentation was considered to have ended. The wines were shelved horizontally and allowed to mature in the bottle for a further seven months. The wines were riddled and disgorged at Simonsig Cellar, Stellenbosch, South Africa. Liqueur d'expédition/Liqueur de dosage was not added and the final brut wines were recapped. A schematic of the MCC winemaking protocol is shown in Fig. 1.

\section{Sensory evaluation}

A free-sorting exercise was performed on the nine-monthold MCC wines. The panel of 30 experts (winemakers, oenologists, postgraduate oenology students and trained consumer panellists) consisted of 15 males and 15 females, ranging in age from 23 to 60 years. Twelve wines from each of the two farms were assessed in 2014, while nine wines were assessed in 2015. The tasting was performed in two sessions (a morning and an afternoon session, each with 15 judges) over two days (one day for the Robertson and another for the Darling wines). The samples were randomised and presented according to a William Latin Square design and coded with a unique three-digit number per judge. Different codes were assigned for the aroma flight and the taste flight. Approximately $20 \mathrm{~mL}$ of each wine was poured into blacktinted tasting glasses (ISO 3591:1977) and covered with plastic Petri dish lids.. The aroma flight was presented first and the taste flight was presented second, with a 15-minute intermission between flights. The judges were instructed to smell/taste the wines, group them according to their similarities, and make a list of the attributes of each group, with a choice to provide individual descriptors for each wine if compelled to do so. The free-sorting exercise performed for the 2014 wines generated aroma and taste descriptors that were used for the sorting exercise for the 2015 wines.

\section{Statistical analysis}

Co-occurrence matrices were generated for the groupings of the wines and for the attributes for each judge. Contingency matrices were used to calculate statistical relationships between treatments and aroma/taste attributes using XLSTAT. Correspondence analysis (CA) was used to visualise the relationship between the treatments and the aroma/taste attributes. Agglomerative hierarchical clustering (AHC) was used to estimate the differences between samples and determine the grouping of treatments.

\section{RESULTS AND DISCUSSIONS}

\section{Aroma sorting of 2014 Méthode Cap Classique wines}

The AHC of the aroma sorting for Darling (grouping indicated by ellipses in Fig. 2) and Robertson (results not shown) showed clear groupings according to temperature. Multidimensional scaling (MDS) showed good repeatability between biological repeats for both farms (a Kruskal's stress-1 of 0.095 for the Darling repeats and 0.161 for Robertson), with the exception of one of the $30^{\circ} \mathrm{C}$ repeats. The Kruskal's stress- 1 needs to be less than 0.2 - the smaller the better. The treatments accounted for $73 \%$ of the observed variance in the Darling aroma sorting for the first two factors (Fig. 2), and only $49 \%$ of the observed variance for Robertson (data not 


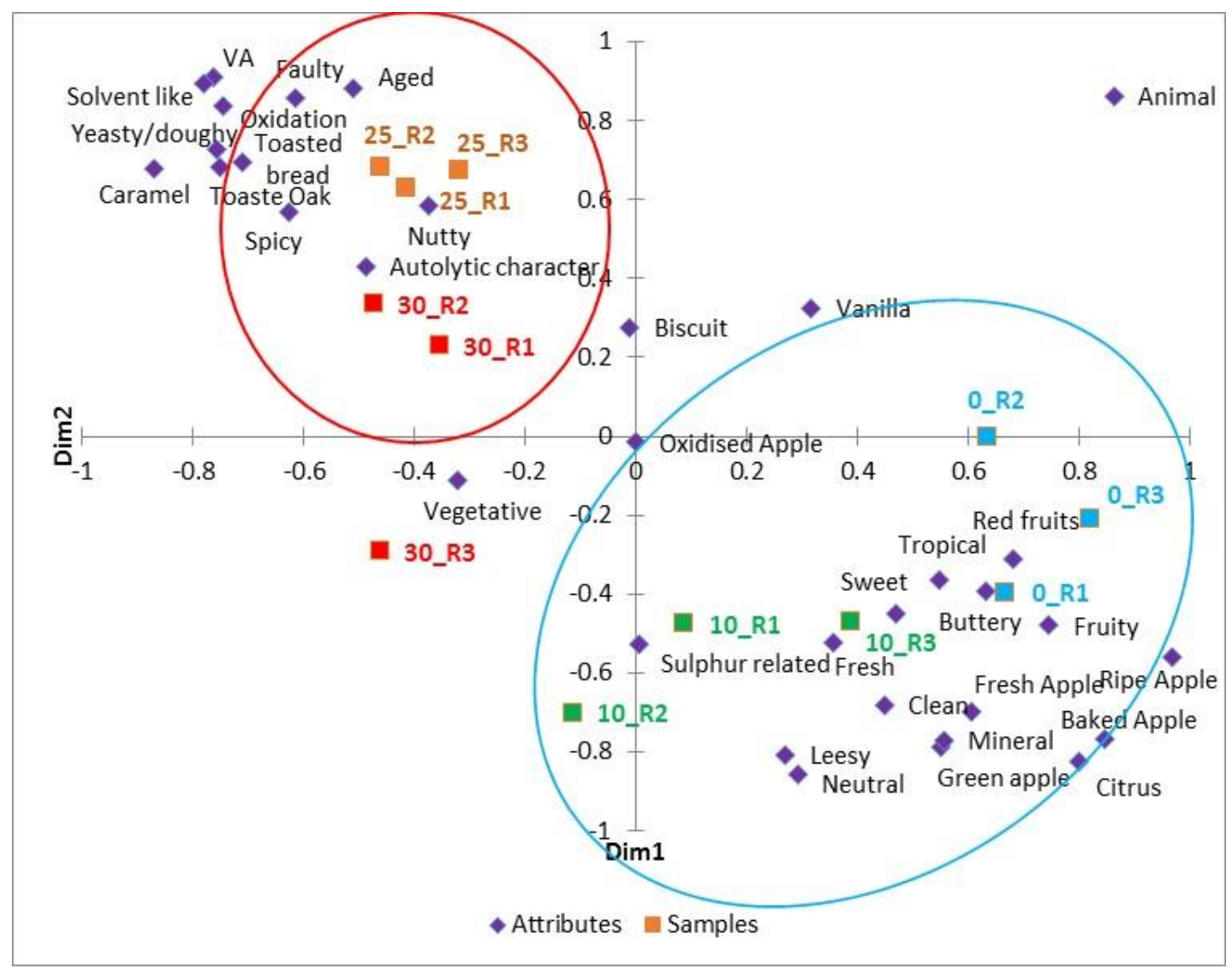

FIGURE 2

A scatterplot of the aroma-sorting results of MCCs made from grapes harvested from Darling in 2014 and stored at $0^{\circ} \mathrm{C}, 10^{\circ} \mathrm{C}$, $25^{\circ} \mathrm{C}$ and $30^{\circ} \mathrm{C}$, with three repeats per temperature. The ellipses are drawn according to the Agglomerative Hierarchical Clustering (AHC) analysis.

shown). Wines from lower temperature treatments had more positive aroma attributes compared to those from higher temperature treatments, and were more frequently described as fruitier and fresher, and generally were aromatically more appealing, in line with the aroma attributes cited for other young (nine month old) TSWs (Vannier et al., 1999; Torrens et al., 2010).

Treatments at higher temperatures were associated with attributes such as 'toasty', 'oaky', 'buttery' and 'vanilla', which were positively similar to those previously cited for 18-month and older TSWs (De la Presa-Owens et al., 1998). The treatments at higher temperatures also had negative aromas, such as 'oxidation', 'chemical' and 'solvent-like', which previously have been linked to oxidised white wines (Silva Ferreira et al., 2003). Negative attributes, such as 'sulphur-related', 'VA', 'solvent-like' and 'oxidation', were the most frequently cited in relation to the treatments at higher temperatures. The outlying 30_R3 treatment in the Darling set was described as 'vegetative', an attribute that has previously been associated with the oxidation of white wines, implying that this particular treatment was oxidised (Silva Ferreira et al., 2003), and this was the possible cause of its placement separate from the other repeats.

Taste sorting of 2014 Méthode Cap Classique wines

The AHC analysis for the taste sorting showed a grouping of the Darling 2014 MCCs according to temperature treatments, similar to the aroma-sorting results (grouping indicated by ellipses in Fig. 3). The MDS showed that the judges were not able to group the MCCs according to taste and for the aroma sorting. Unlike the aroma sorting, the repeatability between biological repeats was poor (Kruskal's stress- 1 of 0.194 for the Darling repeats). The treatments accounted for $64 \%$ of the variation for Darling.

Due to retro-nasal perceptions by the judges, most of the attributes were similar to those generated for the Darling aroma sorting. However, the judges were consistent in generating similar results for the taste as for the aroma, in correlation with the groups of treatments. In terms of mouthfeel and flavour, the judges cited the Darling lower temperature treatments as being 'balanced', 'well developed', 'full bodied' and with 'high acidity', while the higher temperature treatments were found to be acidic/sour, more bitter and sweeter, with a longer after-taste (Fig. 3). The Robertson data (Fig. 4) shows that, upon tasting, the judges were unable to distinguish the wines according to treatments (Kruskal's stress-1 of 0.215 for the Robertson repeats), even given retro-nasal aroma perceptions. Robertson had very poor grouping according to temperature, in relation to which the treatments accounted for only $37 \%$ of the observed variance in the first two components of the correspondence analysis. 


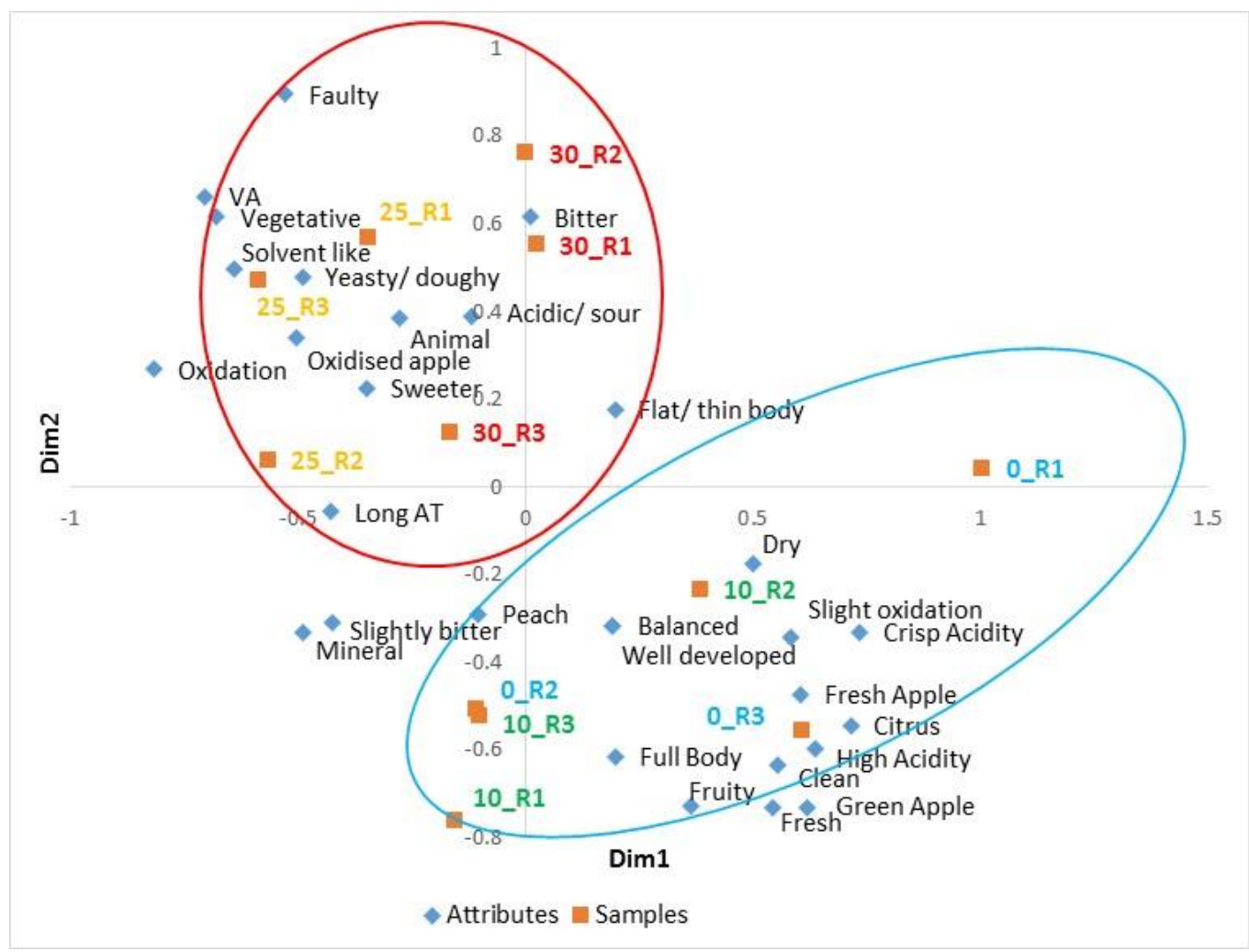

FIGURE 3

A scatterplot of the taste-sorting results for MCCs made from grapes harvested at Darling in 2014 and stored at $0^{\circ} \mathrm{C}, 10^{\circ} \mathrm{C}$, $25^{\circ} \mathrm{C}$ and $30^{\circ} \mathrm{C}$, with three repeats per temperature. The ellipses are drawn according to the AHC analysis. VA - volatile acidity.

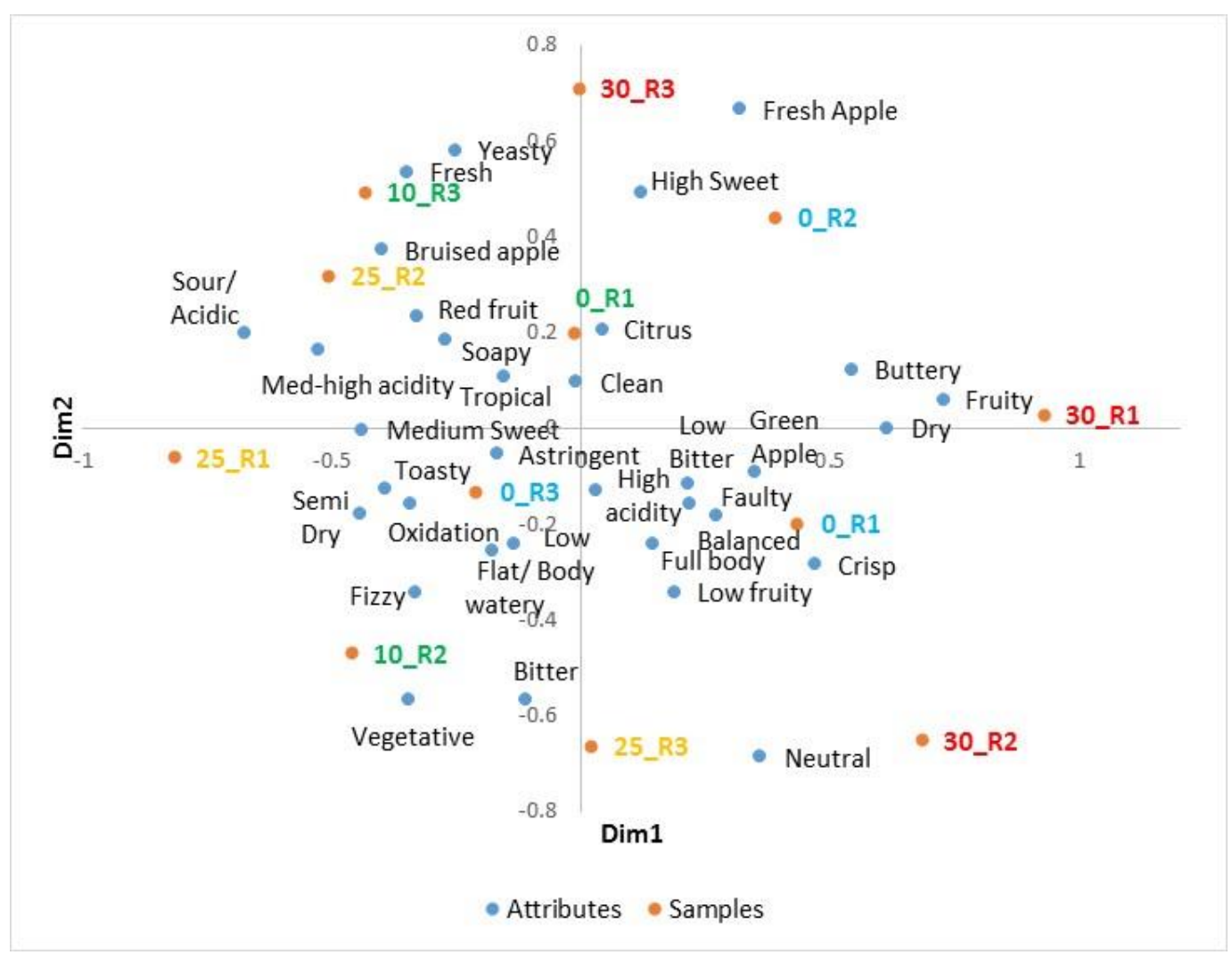

FIGURE 4

A scatterplot of the taste-sorting results for MCCs made from grapes harvested at Robertson in 2014 and stored at $0^{\circ} \mathrm{C}, 10^{\circ} \mathrm{C}$ and $30^{\circ} \mathrm{C}$, with three repeats per temperature. 


\section{Aroma sorting of 2015 Méthode Cap Classique wines}

Due to vinification difficulties, the $25^{\circ} \mathrm{C}$ treatments were removed from the sensory evaluation after a preliminary screening revealed the wines to be oxidised, hence the 2015 sorting exercises were performed on only nine wines. Once more, the AHC analysis showed clear groupings for aroma sorting according to temperature (indicated by ellipses in Figs 5 and 6). Multidimensional scaling (MDS) showed good repeatability between biological repeats for both farms (Kruskal's stress-1 of 0.123 for Darling and 0.108 for Robertson). Unlike in 2014, the aroma profiles of the Robertson wines differed more between the temperature groups compared to the Darling wines. These Kruskal's stress- 1 indices are larger than those calculated in 2014, meaning that the judges were less able to differentiate the aroma of the 2015 MCCs according to temperature treatments.

The sorting analysis for the 2014 wines was done on 12 wines, while for 2015 there were only nine wines. The difference in the number of wines assessed at a time has been shown to influence the statistical coherence of the results, with 12 being the optimum number for achieving results that are more statistically confident (Chollet et al., 2011, 2014).

The treatments at lower temperatures $\left(0^{\circ} \mathrm{C}\right.$ and $\left.10^{\circ} \mathrm{C}\right)$ were again associated with positive aroma attributes. Generally, positive aroma attributes were more frequently cited than negative attributes for all the 2015 treatments compared to those in 2014. The Darling $0^{\circ} \mathrm{C}$ treatments were described by the judges as 'green' and 'baked apple' (Fig. 5), similar to those from the 2014 vintage, whilst the Robertson $0^{\circ} \mathrm{C}$ treatments (Fig. 6) were associated in 2015 with 'oxidation' and 'toasted bread' notes (aside from the 0_R3 outlier), showing different attributes for the treatments between the two farms for this vintage. The $10^{\circ} \mathrm{C}$ treatments from Darling were perceived by the judges to be more 'fresh' and 'fruity', similar to the 2014 aroma-sorting results (Fig. 5). The Robertson $10^{\circ} \mathrm{C}$ treatments, however, were perceived as having attributes similar to those associated with higher temperature treatments, such as 'VA', 'vanilla' and 'caramel' (Fig. 6) in 2014. The Darling $30^{\circ} \mathrm{C}$ treatments again grouped with negative attributes, such as solvent-like, sulphur-related, VA and faulty (Fig. 5), whilst the Robertson $30^{\circ} \mathrm{C}$ treatments were associated with fruity notes such as 'green apple', 'yellow fruit', 'pear' and 'freshness' - notes associated with lower temperature treatments in the previous vintage and for the 2015 Darling aroma profile.

Dissimilar to the 2014 vintage is that the wines made from the lower temperature treatments were associated with 'toasty' and 'caramel' notes, which previously were associated with the higher temperature treatments and commonly associated with older (18 months or more), traditional-style sparkling wines (De la Presa-Owens et al., 1998). Vintage differences are evident in the sensory profile of MCCs. The Robertson 2015 aroma profile was very unique, in that mature TSW attributes, such as 'vanilla', 'yeasty' and 'buttery', were cited throughout all the treatments, with the

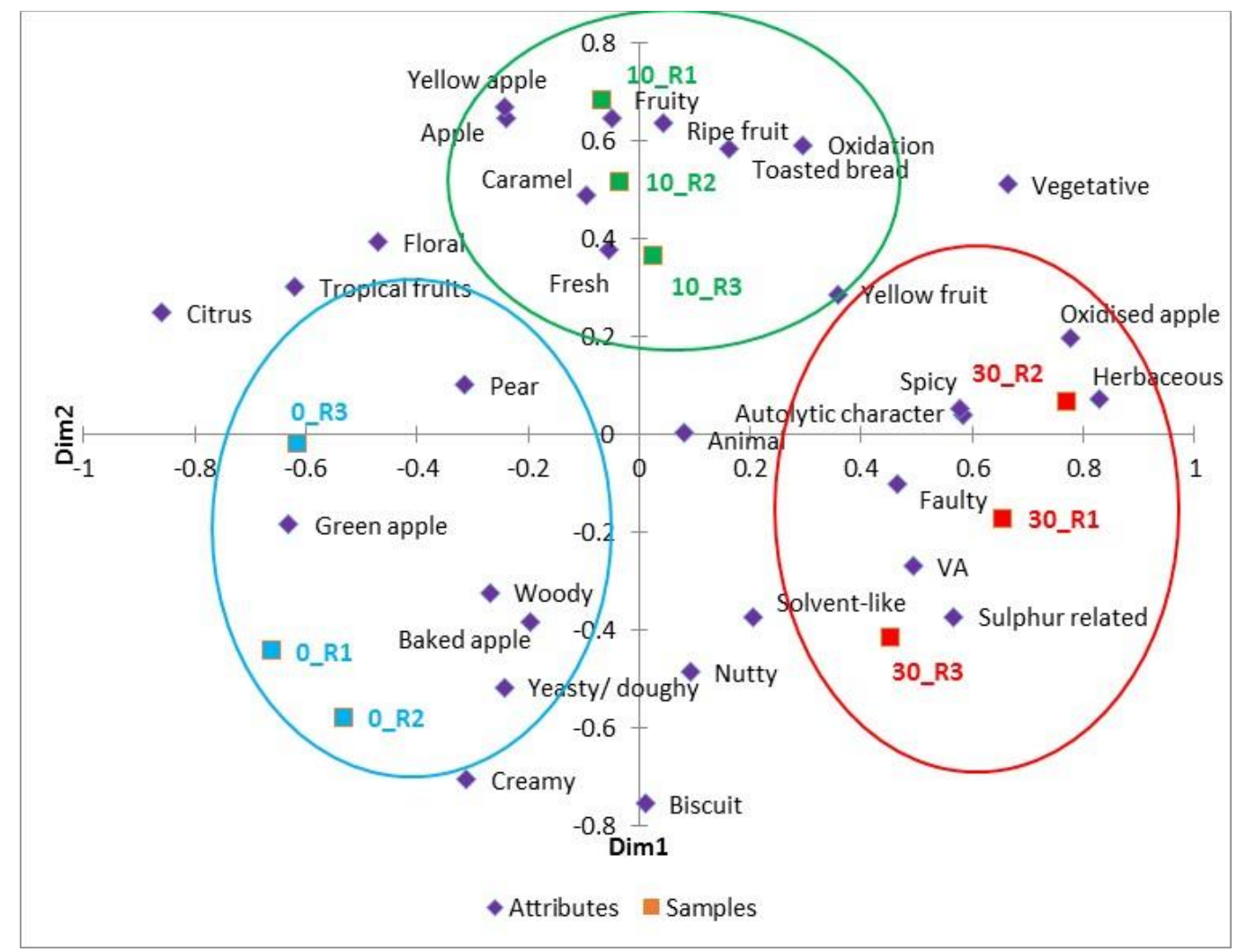

FIGURE 5

A scatterplot of the aroma-sorting results for MCCs made from grapes harvested at Darling in 2015 and stored at $0^{\circ} \mathrm{C}, 10^{\circ} \mathrm{C}$ and $30^{\circ} \mathrm{C}$, with three repeats per temperature. The ellipses are drawn according to the AHC analysis. 


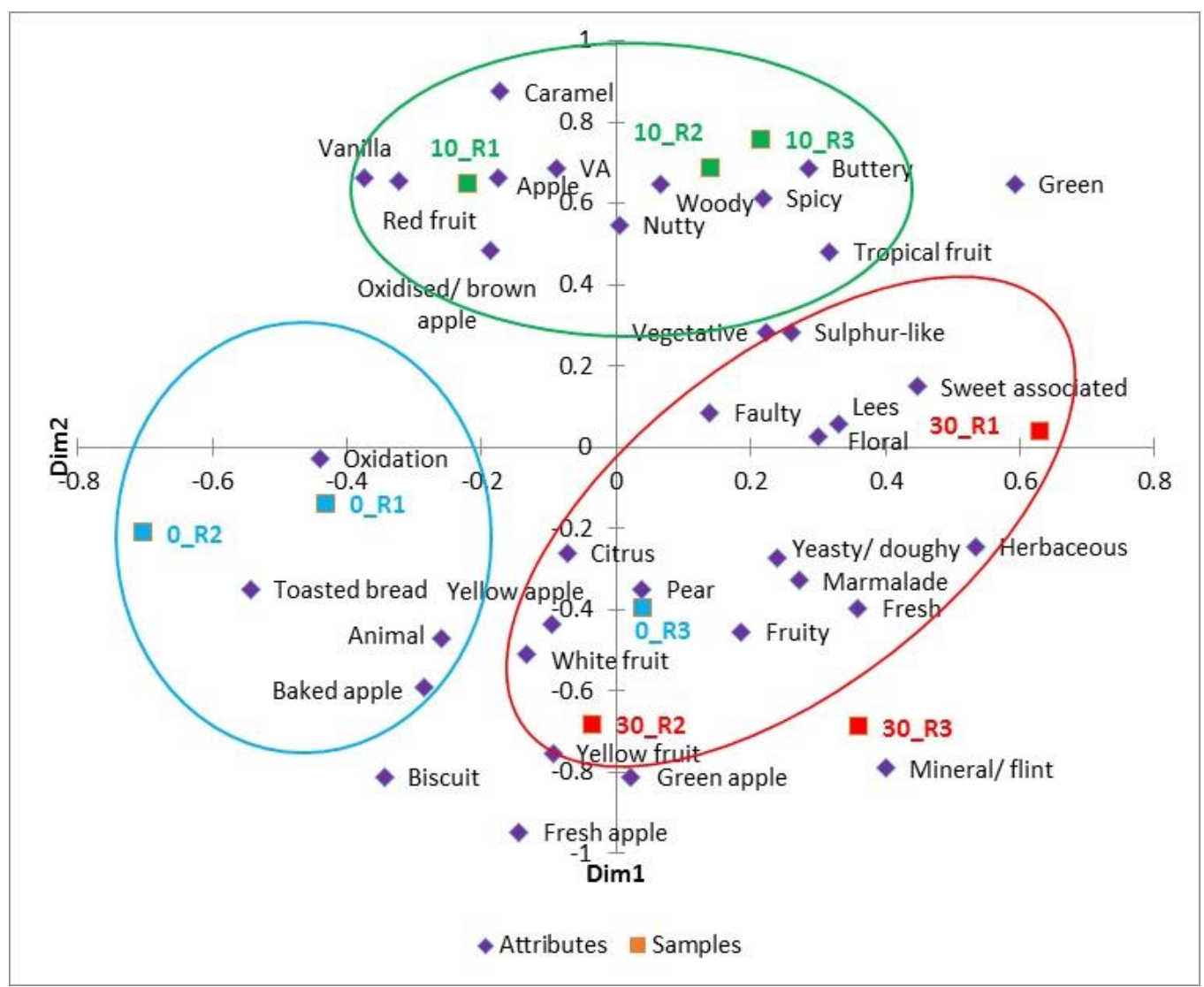

FIGURE 6

A scatterplot of the aroma-sorting results of MCCs made from grapes harvested at Robertson in 2015 and stored at $0^{\circ} \mathrm{C}, 10^{\circ} \mathrm{C}$ and $30^{\circ} \mathrm{C}$, with three repeats per temperature. The ellipses are drawn according to the AHC analysis.

$30^{\circ} \mathrm{C}$ treatments being associated more with fruity/fresh aromas.

\section{Taste sorting of 2015 Méthode Cap Classique wines}

The sorting of Darling (Fig. 7) and Robertson (Fig. 8) MCCs according to taste again showed that the judges were less able to distinguish between treatments according to taste, similar to what was the case in 2014. The AHC of Darling and Robertson showed poor grouping of the wines according to temperature treatments, as revealed in the MDS. Kruskal's stress-1 for both Darling (0.185) and Robertson (0.183) revealed that the taste profiles were perceived as being similar. The similarity between the taste profiles of the 2015 wines was less than that of the 2014 wines, but due to the differences in the sample sizes, the 2014 Darling wines had better groupings than those of 2015 .

A scatterplot of the 2015 Darling taste-sorting results shows that the $0^{\circ} \mathrm{C}$ treatments were similar to those of the aroma of both the $0^{\circ} \mathrm{C}$ and $10^{\circ} \mathrm{C}$ treatments in their fresh and fruity attributes, also due to retro-nasal perception (Fig. 7). Mouthfeel attributes such as 'clean', 'dry' and 'medium body' were associated with the $0^{\circ} \mathrm{C}$ and $10^{\circ} \mathrm{C}$ treatments, similar to the taste sorting in 2014.

The scatterplot also shows that the 2015 taste sorting of the $30^{\circ} \mathrm{C}$ treatment was similar to the 2014 taste attributes ('oxidation', bitterness and 'full body'), but lacked in retro- nasal attributes ('buttery', 'caramel' and 'vanilla'). This matched the aroma profile of the $30^{\circ} \mathrm{C}$ treatment, which only showed negative attributes and no matured TSW attributes in 2014. The taste-sorting exercise for Robertson 2015 (Fig. 8) showed a scattering similar to that of the 2014 vintage (Fig. 4) and the 2015 Darling taste (Fig. 7). The study furthermore showed that, regardless of the judges' level of expertise in TSW in particular, they were able to detect differences in the MCCs according to the temperature treatments due to their extensive exposure to wine as a product category. An aspect that the present study did not explore was the ability of consumers to distinguish the MCCs according to temperature treatments. This aspect would add a very interesting dimension to the study, and possibly help better understand the correlation between expert opinions and consumers' perceptions of MCC wines.

\section{CONCLUSIONS}

The temperature of grapes at the moment of pressing has a greater impact on the aroma of Méthode Cap Classique wines than on their taste. The sensory analysis of wines made from grapes stored at $0^{\circ} \mathrm{C}$ and $10^{\circ} \mathrm{C}$ showed that the wines generally had more desirable aroma attributes, such as fruity, fresh and floral, compared to wines from higher temperature treatments. Grapes stored at $25^{\circ} \mathrm{C}$ and $30^{\circ} \mathrm{C}$ produced wines that were associated with positive aroma 


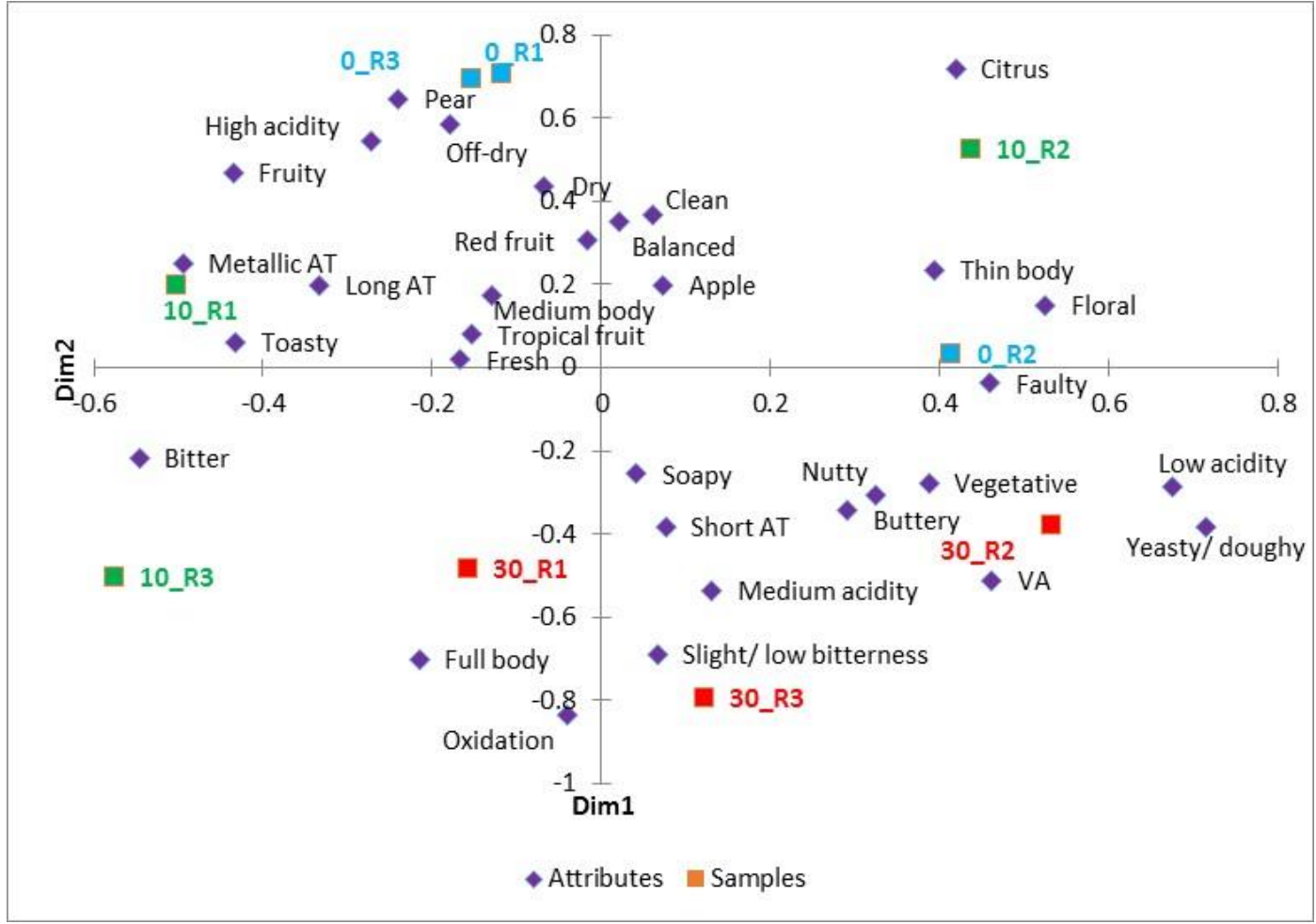

FIGURE 7

A scatterplot of taste-sorting results of the MCCs made from grapes harvested from Darling in 2015 and stored at $0^{\circ} \mathrm{C}, 10^{\circ} \mathrm{C}$ and $30^{\circ} \mathrm{C}$, with three repeats per temperature.

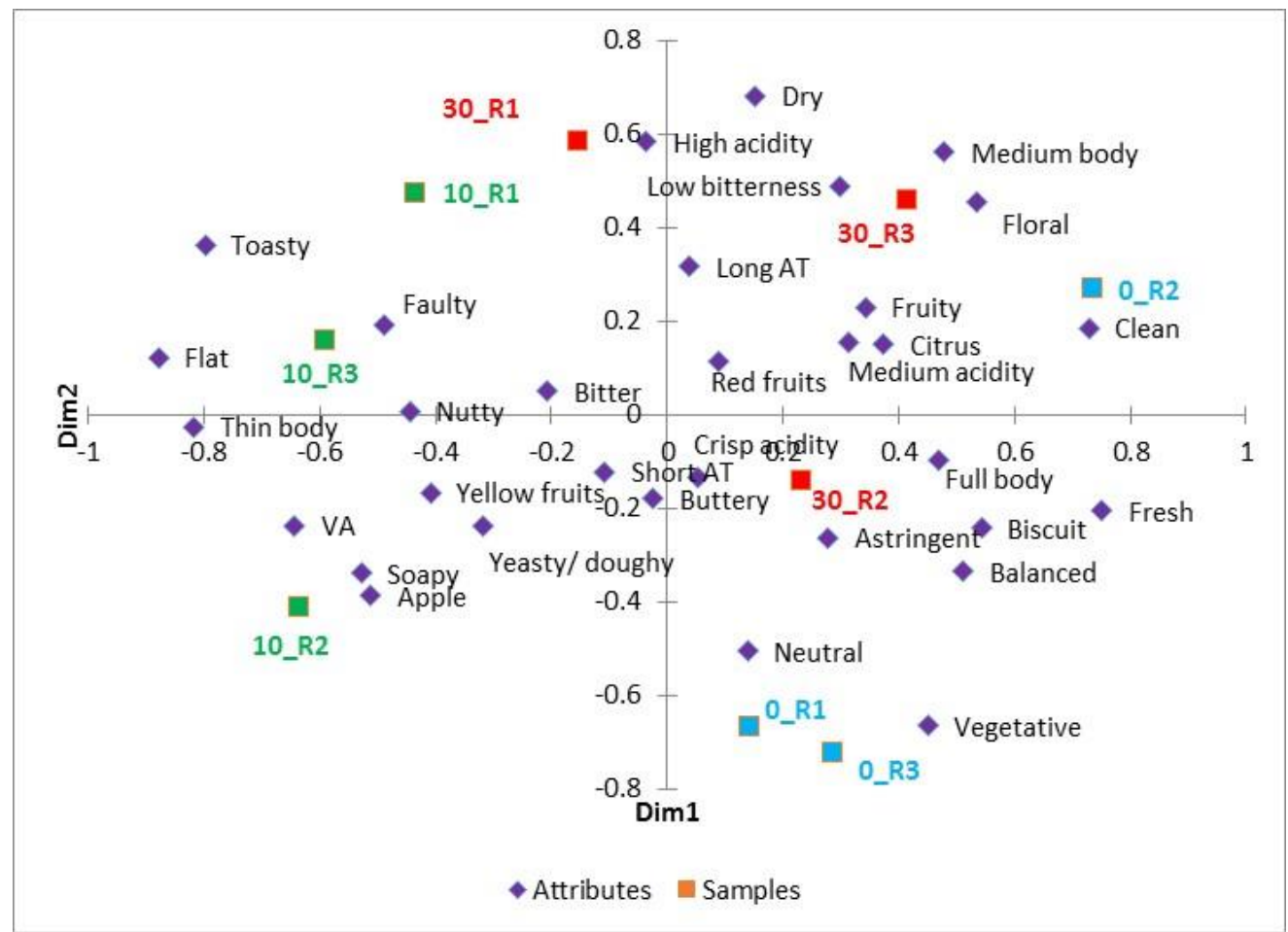

FIGURE 8

Scatterplot of taste-sorting results for MCCs made from grapes harvested at Robertson in 2015 and stored at $0^{\circ} \mathrm{C}, 10^{\circ} \mathrm{C}$ and $30^{\circ} \mathrm{C}$, with three repeats per temperature. 
attributes (i.e. buttery, caramel, oaky and nutty) that are most commonly associated with older, traditional-style sparkling wines, but they also displayed troublesome aroma attributes such as VA, solvent-like and oxidation, which are not expected of wines that are only nine months old. There were clear vintage differences between the 2014 and 2015 wines. Sample size also played a role, hence different dataset sizes for the two vintages may have influenced the ability of judges to distinguish between the treatments. A control experiment, in which the grapes are processed as they arrive, would help provide a "real-life" system with which to compare the treatments. South African MCC winemakers may not need to chill grapes before processing, but the results obtained in this study seem to indicate a clear benefit and a healthier aroma profile for wines produced with chilled grapes. This treatment might be particularly advisable for lower quality grapes in order to better the wine's aroma potential.

\section{LITERATURE CITED}

Anderson, M.M., Smith, R.J., Williams, M.A. \& Wolpert, J.A., 2008. Viticultural evaluation of French and California Pinot Noir clones grown for production of sparkling wine. Am. J. Enol. Vitic. 59, 188-193.

Buxaderas, S. \& López-Tamames, E., 2010. Managing the quality of sparkling wine. In: Reynolds, A. (ed). Managing wine quality, Vol. 2: Viticulture and wine quality. Woodhead Food Series, Canada, pp. 553- 588 .

Charpentier, C., Aussenac, J., Charpentier, M., Prome, J.C., Duteurtre, B. \& Feuillat, M., 2005. Release of nucleotides and nucleosides during yeast autolysis: Kinetics and potential impact on flavor. J. Agr. Food Chem. 53, 3000-3007.

Chollet, S., Lelièvre, M., Abdi, H. \& Valentin, D., 2011. Sort and beer: Everything you wanted to know about the sorting task but did not dare to ask. Food Qual. Prefer. 22, 507-520.

Chollet, S., Valentin, D. \& Abdi, H., 2014. Free sorting task. In: Valera P. \& Ares, G. (eds). Novel techniques in sensory characterization and consumer profiling. Taylor and Francis, Boca Raton. pp. 207 - 227.

De la Presa-Owens, C., Schlich, P., Davies, H.D. \& Noble, A.C., 1998. Effect of methode champenoise process on the aroma of four $V$. vinifera varieties. Am. J. Enol. Vitic. 49, 289-294.

Feuillat, M. \& Charpentier, C., 1982. Autolysis of yeasts in champagne. Am. J. Enol. Vitic. 33, 6-13.

Fornairon-Bonnefond, C., Camarasa, C., Moutounet, M. \& Salmon, J.M., 2002. New trends on yeast autolysis and wine aging on lees: A bibliographic review. J. Int. Sci. Vigne Vin 36, 49-69.

Francioli, S., Torrens, J., Riu-Aumatell, M., López-Tamames, E. \& Buxaderas, S., 2003. Volatile compounds by SPME-GC as age markers of sparkling wines. Am J. Enol. Vitic. 54(3), 158-162.

Hidalgo, P., Pueyo, E., Pozo-Bayón, M.A., Martínez-Rodríguez, A.J., Martín-Alvarez, P. \& Polo, M.C., 2004. Sensory and analytical study of rosé sparkling wines manufactured by second fermentation in the bottle. J. Agric. Food Chem. 52, 6640-6645.
White, M.R.H. \& Heymann, H., 2015. Assessing the sensory profiles of sparkling wine over time. Am. J. Enol. Vitic. 66(2), 156-163.

Marais, J. (2001). Effect of grape temperature and yeast strain on Sauvignon blanc wine aroma composition and quality. S. Afr. J. Enol. Vitic. 22(1), 4750 .

Martínez-Lapuente, L., Guadalupe, Z., Ayestarán, B., Ortega-Heras, M. \& Pérez-Magariño, S., 2013. Sparkling wines from alternative red and white varieties. Am. J. Enol. Vitic. 64:1, 39-49.

Martínez-Rodríguez, A.J. \& Pueyo, E., 2009. Sparkling wines and yeast autolysis. In: Moreno-Arribas, M.V. \& Polo, M.C. (eds.). Wine chemistry and biochemistry. Springer, New York. pp. $61-80$.

Martínez-Rodríguez, A.J., Carrascosa, A.V. \& Polo, M.C., 2001. Release of nitrogen compounds to the extracellular medium by three strains of Saccharomyces cerevisiae during induced autolysis in a model wine system. Int. J. Food Microbiol. 68, 155-160.

Martínez-Rodríguez, A.J., Carrascosa, A.V., Martín-Àlvarez, P.J., MorenoArribas, M.V. \& Polo, M.C., 2002. Influence of the yeast strain on the changes of the amino acids, peptides and proteins during sparkling wine production by the traditional method. J. Ind. Microbiol. Biot. 29, 314-322.

Newton, S., 2010. Sparkling wine: The growth of this category of wine in South Africa. Thesis, Cape Wine Academy, PO Box 425, Stellenbosch, 7599 .

OIV, 2016. International Code of Oenological Practices: Sparkling wines [Online]: www.oiv.int/en/technical-standards-and-documents/oenologicalpractices/oenological-practices-sparkling-wines [accessed 18 Feb 2017].

Pérez-Magarino, S., Ortega-Heras, M., Martínez-Lapuente, L., Guadalupe, Z. \& Ayestarán, B., 2013. Multivariate analysis for the differentiation of sparkling wines elaborated from autochthonous Spanish grape varieties: Volatile compounds, amino acids and biogenic amines. Eur. Food Res. Technol. 236, 827-841.

Polidori, G., Jeandet, P. \& Liger-Belair, G., 2009. Bubbles and flow patterns in champagne. Am. Scientist 97, 294-296.

Pueyo, E., Martin-Alvarez, P.J. \& Polo, M.C., 1995. Relationship between foam characteristics and chemical composition in wines and cavas (sparkling wines). Am. J. Enol. Vitic. 46(4), 518-524.

Reynolds, A., Cliff, M., Girard, B. \& Kopp, T.G., 2001. Influence of fermentation temperature on composition and sensory properties of Semillon and Shiraz wines. Am. J. Enol. Vitic. 52(3), 235-240.

Silva Ferreira, A.C., Oliveira, C., Hogg, T. \& Guedes de Pinho, P., 2003. Relationship between potentiometric measurements, sensorial analysis, and some substances responsible for aroma degradation of white wines. J. Agric. Food Chem. 51, 4668-4672.

Torrens, J., Riu-Aumatell, M., Vichi, S., López-Tamames, E. \& Buxaderas, S., 2010. Assessment of volatile and sensory profiles between base and sparkling wines. J. Agric. Food Chem. 58, 2455-2461.

Vannier, A., Brun, O.X. \& Feinberg, M.H., 1999. Application of sensory analysis of champagne wine characterization and discrimination. Food Qual. Pref. 10, 101-107.

Zoecklein, B., 2002. A review of Méthode Champenoise production. Virginia Cooperative Extension. 